\title{
Effectiveness of Variable Message Signs on Driving Behavior Based on a Driving Simulation Experiment
}

\author{
Xuedong Yan and Jiawei Wu \\ MOE Key Laboratory for Urban Transportation Complex Systems Theory and Technology, Beijing Jiaotong University, \\ Beijing 100044, China
}

Correspondence should be addressed to Xuedong Yan; xdyan@bjtu.edu.cn

Received 14 November 2013; Accepted 24 January 2014; Published 13 March 2014

Academic Editor: Wuhong Wang

Copyright (c) $2014 \mathrm{X}$. Yan and J. Wu. This is an open access article distributed under the Creative Commons Attribution License, which permits unrestricted use, distribution, and reproduction in any medium, provided the original work is properly cited.

\begin{abstract}
Variable message signs (VMSs), as one of the important ITS devices, provide real-time traffic information of road network to drivers in order to improve route choice and relieve the traffic congestion. In this study, the effectiveness of VMS on driving behavior was tested based on a driving simulation experiment. A road network with three levels of VMS location to route-diverging intersection and three types of VMS information format was designed in a high fidelity driving simulator platform. Fifty-two subjects who were classified by driver age, gender, and vocation successfully completed this experiment. The experimental results showed that driver characteristics, VMS location, and information format profoundly influence driving behaviors. Based on the research findings, it is suggested that VMS would be positioned between $150 \mathrm{~m}$ and $200 \mathrm{~m}$ upstream of the diverging point to balance the VMS effects on traffic safety and operation and the graphic information VMS format is better than the format with text massage only.
\end{abstract}

\section{Introduction}

With the rapid development of urbanization and motorization, China has become the world's second largest car country and the constantly climbing number of vehicles in urban road networks leads to more and more serious traffic congestion problems. The traditional countermeasures of traffic congestion alleviation include constructing new roadways, adding new traffic facilities, and strengthening traffic management [1]. While the effects of the traditional methods are limited in the cities with high vehicle ownership, the technologies of intelligent traffic systems (ITS) have been widely applied to solve traffic issues [2]

Variable message signs, as an advanced traffic guidance system, can provide real-time traffic information in urban road networks to help drivers choose the routes with lower traffic volumes. Thus, the vehicles can be distributed reasonably in road networks so as to improve the performance of traffic system [3,4]. With the assistance of VMSs, the road capacity can be increased noticeably and the utilization efficiency of downstream off-ramp can be enhanced [5]. However, VMS effectiveness is depentdent on drivers' route choice behavior, and VMS design and position may influence lane changing and speed control behaviors. The behaviors represent the drivers' perception to the guidance information and the trust degree to the information [6]. Therefore, it is critical to investigate how the interface type, sign position, and guidance information formats of VMS affect driving behaviors in urban road networks.

A number of previous studies focusing on VMSs and relevant driving behaviors have been conducted. Two typical research methods, questionnaire, and computer simulation experiment have been applied for analyzing main factors that influence drivers' route choices in the VMS environments. Through the questionnaire, it was found that whether drivers accept an item of VMS advice or not is closely associated with drivers' characteristics and their familiarity degree to the road network $[7,8]$. Generally, the acceptance rates of drivers who are unfamiliar with the road network are higher than the familiar drivers because the familiar drivers may select driving route based on experience rather than guidance information only $[8,9]$. The drivers' personal attributes, such as age, gender, and driving age can also significantly affect the driving behaviors in discovering, understanding, and complying with the guidance information as the travel characteristics of selected routes change [10-13]. Similar to the survey 
TABLE 1: Gender and vocation distribution of recruited subjects.

\begin{tabular}{lccc}
\hline Gender & Professional & Unprofessional & Total \\
\hline Male & 16 & 14 & $30(57.7 \%)$ \\
Female & 9 & 13 & $22(42.3 \%)$ \\
\hline Total & $25(48.1 \%)$ & $27(51.9 \%)$ & $52(100 \%)$ \\
\hline
\end{tabular}

results from questionnaire, the study based on the computer simulation experiment also showed that the factors including characteristics of guidance information and attributes of drivers would affect drivers' route choice [14]. Additionally, the techniques of questionnaire and simulation experiment were also used to optimize VMS design in the road network. It was found that VMSs' information presentation formats, including numerical format, the text description format, and switch-on-light format, may lead to drivers having different comprehension on traffic status of road networks [15]. The computer simulation experiment result indicated that if VMS releases a clear suggestion strategy of route choice, the rate of drivers' choosing suggested routes is higher than that without strategy [16]. Furthermore, Srinivasan and Jocanis conducted computer simulation experiments to investigate drivers' attention demands of four types of turn-by-turn route guidance displays. The results showed that the most effective and preferred VMS display was the one using countdown bars representing distance from the turn location to supplement text message [17].

While the statement preference (SP) methods of questionnaire and computer simulation experiment are limited to provide detailed driving behavior data, driving simulators were applied to investigate drivers' speed control, lane change, and response to VMSs in virtual reality road environments. Driving simulators can provide a well-controlled experimental condition to compare the drivers' behaviors in road networks with different VMS settings. Another advantage of using driving simulator is that it can collect the data which are difficult to achieve in the real world, especially the vehicle's instantaneous velocity [18]. Based on driving simulator experiments, Kolisetty et al. used a driving simulator to study driving speed behavior under VMS and found that VMSs had an effect on subjects with average speed changes from -2 to $15 \mathrm{~km} / \mathrm{h}$ with VMSs compared to without [19]; Jamson et al. evaluated the effects of VMS on driver performance and safety, who pointed out that drivers needed to reduce their speed in order to read four-line monolingual and four-line bilingual text-based signs [20]. Lee and Abdel-Aty designed 24 scenarios in a driving simulator and showed that variable speed limits combined with VMSs were beneficial in reducing speed variation and lowering congestion [21]. Meanwhile, they also found age difference in the reaction to VMSs in the experiments. Erke et al. observed that lane changing behavior happened more frequently in the road network with VMSs than the network without VMSs [22].

Although a few of previous studies involved drivers' behaviors in the VMS traffic environment, there is a lack of research focusing on investigating how VMS position and information format affect driving behavior, especially using a high fidelity driving simulator. The main objective of this paper is to investigate whether and how VMS position and VMS information format impact drivers' behaviors, such as route choice, speed control, and lane changing, based on a high fidelity driving simulation experiment.

\section{Methodology}

2.1. Participants. A total of 57 test subjects were recruited in this experiment. Every subject would encounter the VMSs six times and there were 342 samples that reflect the drivers' performances under VMS. The similar scale of sample sizes was also applied in the driving simulator experiments by previous simulator experiment designs [23, 24]. All of the subjects were local drivers in Beijing, China, with at least one year of driving experience and at least 2500 kilometers annual driving distance. Before the experiment, the drivers were tested and proved that they understand the meaning and function of the VMSs applied in Beijing. Finally, 52 drivers successfully finished but five subjects could not complete the experiment due to driving simulation sickness whose data were excluded from collection. According to subjects' vocations, the 52 drivers were classified into two groups, 25 professional drivers and 27 unprofessional drivers. The subject gender distribution was balanced in each vocation group, as shown in Table 1. Each subject was required to test three driving scenarios (it took about an hour to finish the experiment) and was compensated with 500 Chinese RMB for their participation.

2.2. Apparatus/Equipment. A high fidelity driving simulator located in MOE Key Laboratory for Urban Transportation Complex Systems of the Beijing Jiaotong University was used in the study, as shown in Figure 1. The driving simulator has a linear motion base capable of operation with one degree of freedom. It is composed of a visual system with 300 degrees of front view and three rear view mirrors, a full-size cabin of Ford Focus with real operation interface, a digital sound simulation system, a vibration system, and the center console. The visual system allows resolution equal to $1400 \times 1050$ pixels for each channel. The software, including Simvista and Simcreator, is provided for modeling road networks and driving scenarios. The data sampling frequency is up to $60 \mathrm{~Hz}$.

In addition, five cameras are installed inside and outside the cabin to supervise the experimental process. An emergency stop button is installed both inside cabin beside the driver seat and in the front of control desk in order that either subject or researcher can discontinue the experiment immediately in case the subject suffers driving simulation sickness.

2.3. Road Network and Driving Scenario Design. To investigate the effectiveness of VMS on driving behavior, a road network was designed, as shown in Figure 2, which was composed of four-lane road segments with 80 kilometers speed limit and signalized intersections. The network can be divided into two parts. The first part was designed for testing how VMS-I and its location (distance to intersection) 

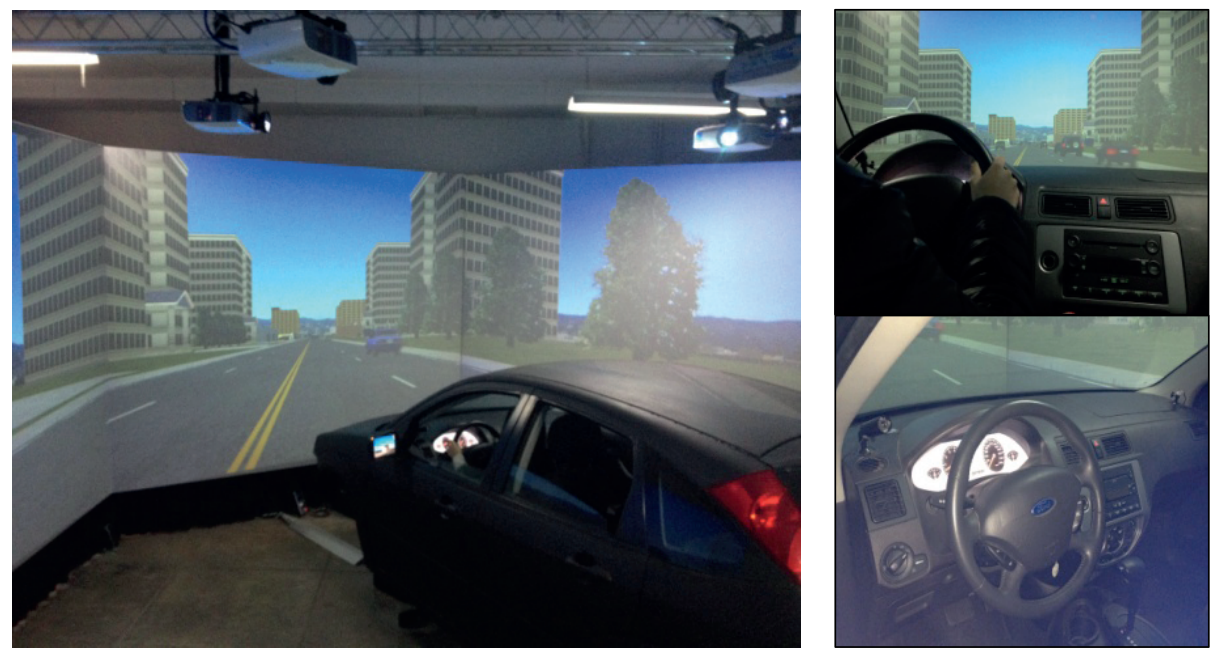

FIgURE 1: The driving simulator.

TABLE 2

\begin{tabular}{lcc}
\hline Scenario & $\begin{array}{c}\text { The first part } \\
\text { VMS-I location }\end{array}$ & $\begin{array}{c}\text { The second part } \\
\text { VMS-II information format }\end{array}$ \\
\hline A & $0 \mathrm{~m}$ & Text-only format \\
B & $200 \mathrm{~m}$ & Graphics-only format \\
C & $400 \mathrm{~m}$ & Combination of text and graphics \\
\hline
\end{tabular}

affect drivers' route choice, speed control, and lane changing behaviors. The distance between VMS-I and signalized intersection were set as $0 \mathrm{~m}, 200 \mathrm{~m}$, and $400 \mathrm{~m}$ for three driving scenarios, respectively. In each scenario, VMS-I released the same content in the graphic format (see Figure 2). The graphic format displayed the current congestion state of selectable routes in the network, in which green color represents smooth and red color represents jam. The graphic format of VMS is most frequently applied in Beijing. The second part of the simulated network was designed to investigate the impact of information delivery format of VMS-II on the driving behaviors. There were three kinds of information formats tested in this experiment, including text-only, graphics-only, and combination of text and graphics. In the VMS-II, the text-only format released the information "800 METERS AHEAD - TRAFFIC CONGESTION"; the graphics format displayed the current congestion state of selectable routes, which is the same design as VMS-I; the combination format of text and graphics displayed both the current congestion state of selectable routes and suggestion of route information with text "TRAFFIC CONGESTION - PLEASE DETOUR SUZHOU ROAD." The three formats of VMS-II were located at 200 meters ahead from the intersection and tested in the three driving scenarios, respectively. The three scenarios were coded as A, B, and C, as summarized in Table 2.

In each driving scenario, subjects needed to drive from the start point to the end points, as illustrated in Figure 2. The distance from start point to the VMS-I location is $1500 \mathrm{~m}$, which is sufficient for drivers to accelerate to their normal driving speeds. Since subjects departed the driving simulator in the inside lane at the start point, if drivers wanted to choose the routes which were not congested, they needed to change from inside lane into outside lane before approaching the intersections. In order to avoid that the signal lights changes disturb subjects' route choice decisions, the signal lights always kept green along each driving route. In addition, to make the driving scenarios seem more realistic, a number of vehicles were design downstream of the intersection, where the segment was displayed as congestion state in the VMS. When subjects approached the intersection, the proximity sensor would trigger the vehicles driving at $5 \mathrm{~km} / \mathrm{h}$ along the segment, which caused subjects to percept traffic congestion. If subjects selected the congested route, the vehicles would restore to normal driving speed around $80 \mathrm{~km} / \mathrm{h}$ after traveling one kilometer forward. The design of traffic congestion and driving scenario was shown in Figure 3.

2.4. Experimental Procedure. Upon arrival, the subjects were asked to fill out and sign an informed consent form (per IRB). The subjects were then advised to drive and behave as they normally would and to adhere to traffic laws as in real life situations. The subjects were also notified that they could quit the experiment at any time in case of driving simulation sickness or any kind of discomfort. Prior to the formal experiment, drivers were trained for at least $10 \mathrm{~min}$ to familiarize with the driving simulator operation and the experimental road network. During the course of the practice, subjects exercised selected maneuvers including straight driving, acceleration, deceleration, left/right turn, and other basic driving behaviors. Then, the formal experiments began during which all subjects would test the three scenarios A, B, and $\mathrm{C}$ in a random order so as to eliminate the experimental time order effect. For security and liability reasons, each subject was escorted to the simulator cabin to commence the experiment and he/she was allowed at least $20 \mathrm{~min}$ to rest before running the next scenario. 


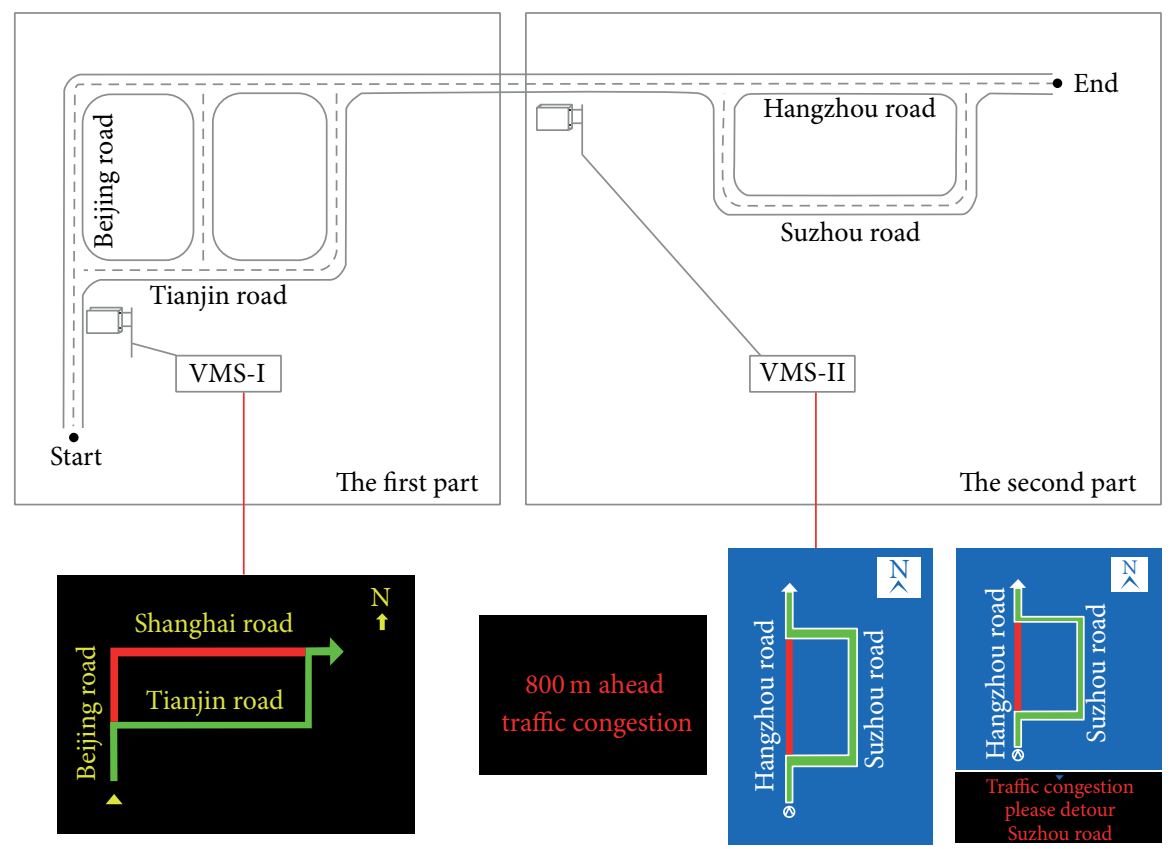

FIGURE 2: The experimental road network.
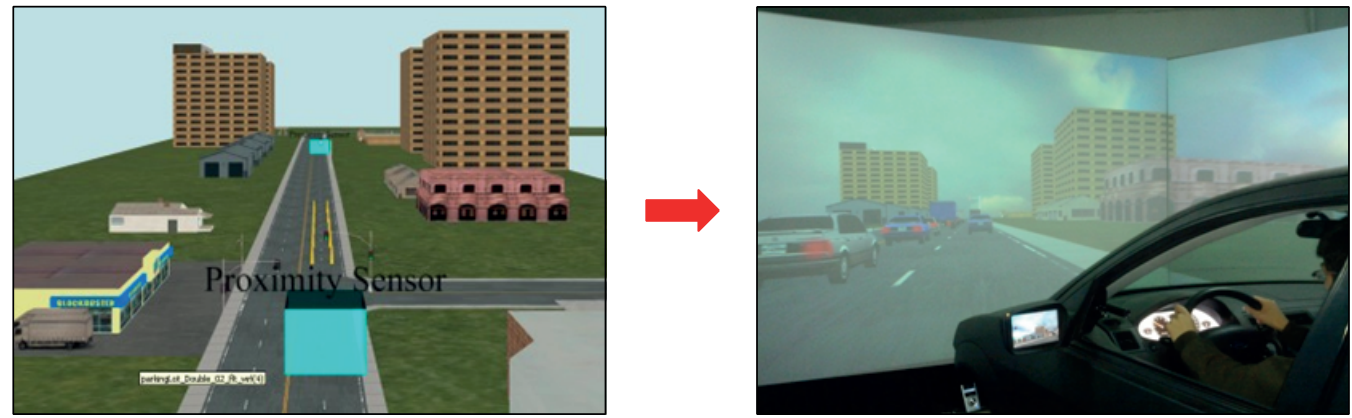

FIgURE 3: The design of traffic congestion and driving scenario.

2.5. Dependent Measures. Data collection and analyses were based on each subject driving three times in the simulated road network. Each subject would meet the different types of VMSs six times for a total of 312 route choices. The related dependent measures for driving behavior analyses were defined as follows:

(i) $\mathrm{RC}$ (straight $=0$; turn $=1$ ): route choice, whether a driver went straight or turned at an intersection;

(ii) SPEED $(\mathrm{km} / \mathrm{h})$ : the vehicle's average speed for every twenty meters upstream or downstream of the VMS;

(iii) SV $(\mathrm{km} / \mathrm{h})$ : speed under VMS, the vehicle's operation speed under VMS;

(iv) LCT (s): lane changing time, which was measured as lane changing duration if a subject has a lane changing behavior; (v) LCP (m): lane changing position, which was measured as the distance to the intersection at which a subject started changing lane if a subject has a lane changing behavior;

(vi) LCL (m): lane changing length, which was measured as the longitudinal distance of lane changing;

(vii) LCS $(\mathrm{km} / \mathrm{h})$ : lane changing speed, which was measured as the average speed during lane changing;

(viii) LCD $\left(\mathrm{m} / \mathrm{s}^{2}\right)$ : lane changing deceleration, which was measured as the average deceleration during lane changing.

Based on the driving behavior data, the following results focused on studying the effects of VMS position, VMS information delivery formats, subject vocation, gender, and age on driving behaviors. The hypothesis testing in the following analyses are based on a 0.05 significance level. 


\section{Experiment Results and Discussion}

3.1. Route Choice Analyses. The binary logistic model is suitable for analyzing route choice behavior because the behavior can be described as a dichotomy variable. The binary logistic regression technique has been applied to explore the relationship between route choice and its potential influencing factors [25-27]. In this study, the parameter estimates of logistic regression models for VMS locations and information formats are shown in Table 3, respectively, where the odds ratios $\operatorname{Exp}(B)$ in the table is defined as the ratio of turn decision likelihood to keeping-straight likelihood.

In the first part for VMS-I analysis, the regression results indicate that the independent variables of age $(P<0.001)$, gender $(P=0.009)$, VMS location (in the case of $400 \mathrm{~m}$ versus $0 \mathrm{~m}: P=0.009)$, and SV $(P=0.014)$ are significantly associated with route choice behavior (turn decision versus keeping-straight decision). The odds ratio estimation of age is 0.924 , which means that as the driver age increases, the probability of making turn a decision decreases. In other words, the older drivers are less willing to change driving route and the VMS guidance is less effective for them. This conclusion is consistent with the previous finding [28] but is opposed to another research result, which showed that older road users are most concerned about VMS [10]. Compared to female drivers, the male drivers have a higher turn decision rate. Therefore, the male drivers are more likely to be influenced by VMS, which is also consistent with the previous finding [28].

In the second part for VMS-II analysis, the regression results indicate that the independent variables of age $(P=$ $0.007)$, vocation $(P=0.012)$, VMS information format (in the case of text-only versus text and graphics: $P=0.046$ ), and SV $(P<0.001)$ are significantly associated with route choice behavior (turn decision versus keeping-straight decision). The age effect of VMS-II is similar to that of VMS-I. The odds ratio estimation of vocation is 7.896. It means that the professional drivers have a much higher turn decision rate than unprofessional drivers, indicating that the professional drivers are more likely to accept the information released by VMS.

According to the two logistic regression models, VMS location, VMS information formats, and speed under VMS are other three important factors that influence drivers' route choice decision. In order to illustrate how VMS location and VMS information format impact the route choice behavior, Figure 4 shows the probability of drivers' making turn decision in the case of 30-year female unprofessional drivers. It depicts that the larger speed under VMS is the less possibility that drivers choose the turn decisions. One possible explanation is that when driving too fast, drivers pay more attention to the forward road surroundings than the information released by VMSs. The other possible explanation is that if the approaching speed to intersection is too high, drivers may take more risks for changing lane to make turns at the intersection. According to Figure 4(a), it is apparent that there is a gap between 0 and 200 meters curves and 400 meters curve. It indicates that the farther distance between VMS-I and intersection, the less possibility that drivers make turn decisions. However, when the distance between VMS-I and intersection is less than $200 \mathrm{~m}$, the effect of VMS-I location will be insignificant for route choice. In Figure 4(b), when VMS information format is graphics-only, drivers are more willing to make turn decisions while drivers are not sensitive to the word message. As long as the VMS information format includes graphics road network with real-time traffic conditions, whether the VMS contains the suggested text information is not significant.

3.2. Speed Control Behavior Analysis. In terms of speed control behavior, this analysis focuses on the driving speed around VMS-I. The mean of the speed under VMS is $67.59 \mathrm{~km} / \mathrm{h}$, and the standard deviation is 13.12 . In the cases that VMS-I's location is $0 \mathrm{~m}$ and $200 \mathrm{~m}$ from the intersection, the drivers' speed control behavior would be influenced by the intersection because they often decelerate to negotiate with the slow downstream traffic. This may confuse the VMS's effect on speed control. Therefore, the scenario C (VMSI's location is $400 \mathrm{~m}$ from the intersection) is used for the analysis of speed behavior in the VMS environment. The average speed curve before and after VMS-I is shown in Figure 5. It illustrate that when drivers were approaching to VMS-I, the average speed at the beginning were increasing; however once the drivers reached 70 meters away from the VMS, the average speed had a slightly downward trend, which reflects the VMS influence on the drivers' speed control behavior. The speed curve indicates that on average, drivers perceive the VMS information and make their route choice decisions at $70 \mathrm{~m}$ upstream of VMS location.

3.3. Lane Changing Behavior Analysis. The measures of LCT, LCP, LCL, LCS, and LCD are used for exploring how VMS position and information format affect drivers' lane changing behaviors in different scenarios. The basic statistical descriptions for LCT, LCP, LCL, LCS, and LCD are summarized in Table 4. In addition, the multivariate analysis of variance (MANOVA) was conducted to analyze the effect of VMS location and VMS information format on the lane changing behavior, as shown in Table 5 .

For the VMS-I, only LCD is significantly influenced by VMS location $(F=8.249, P<0.01)$. As shown in Figure 6, when the VMS is located at the intersection $(0 \mathrm{~m})$, the lane changing deceleration rate is obviously higher than the other two situations $(M=1.09$, S.D. $=0.7$ versus $M=0.53$, S.D. $=0.39$ and $M=0.51$, S.D. $=0.37)$. However, there is no obvious difference in LCD between the locations of 200 meters and 400 meters. The result indicate that if the VMS is located close to intersection, drivers perceive VMS information and make changing route decision too late so that drivers have no sufficient deceleration distance to the intersection, leading to more abrupt lane changing behaviors. Therefore, it is not appropriate to position VMS too close to diverging points in terms of traffic safety.

For the VMS-II, it is found that LCT $(P=0.065$, marginally significant), LCP $(P=0.001)$, LCL $(P=0.003)$, and LCS $(P=0.001)$ are significantly influenced by the VMS information format. However, it has no significant effect on 


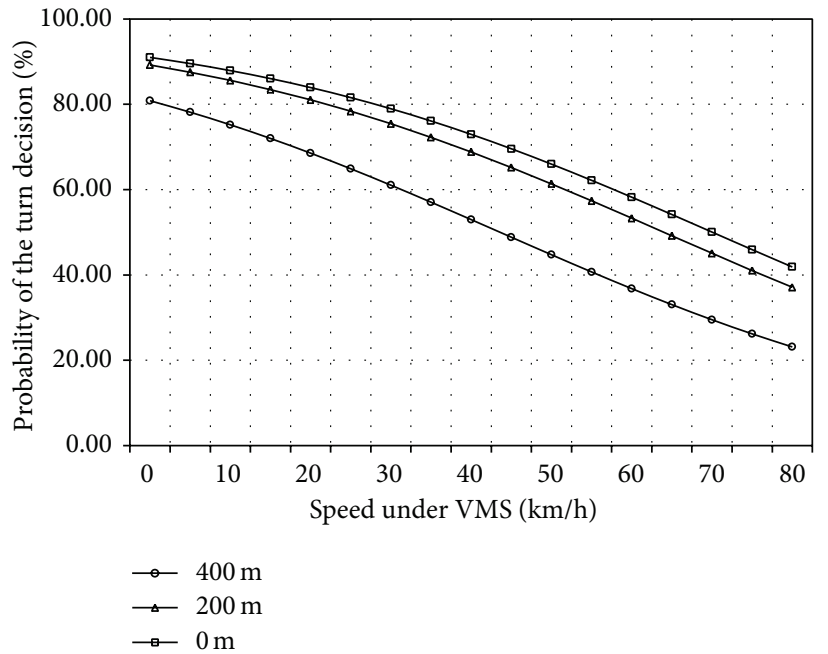

(a) VMS location

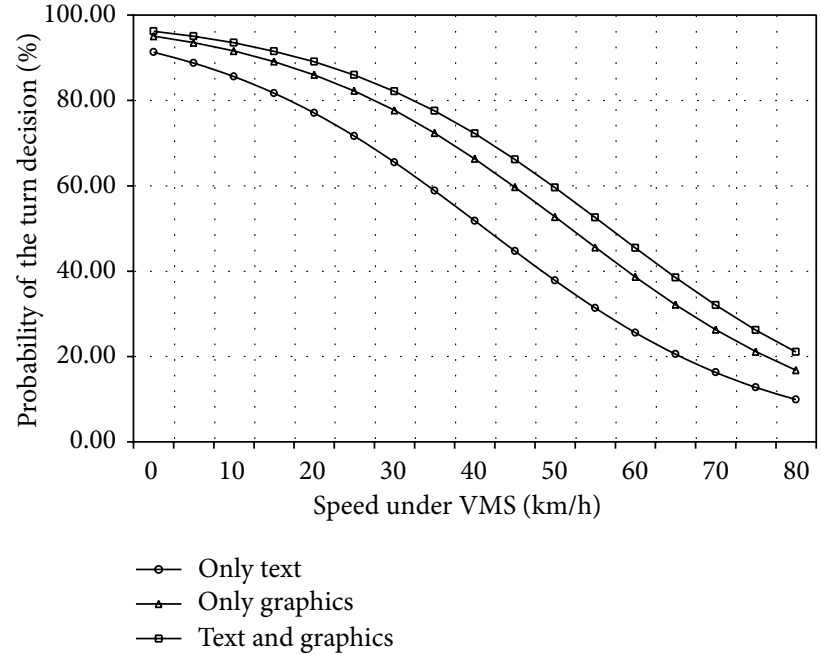

(b) Information format

FIgURE 4: Probability of turn decision based on the logistic regression models.

TABle 3: Parameter estimates of logistic regression models for route choice.

\begin{tabular}{|c|c|c|c|c|c|c|c|c|}
\hline Mode & Variable & Level & $B$ & S.E. & Wald & Df & Sig. & $\operatorname{Exp}(B)$ \\
\hline \multirow{7}{*}{ The first part (VMS-I) } & Age & Continuous & -0.079 & 0.020 & 16.212 & 1 & 0.000 & 0.924 \\
\hline & Gender & Male versus female & 0.968 & 0.370 & 6.836 & 1 & 0.009 & 2.633 \\
\hline & Location & - & - & - & 4.347 & 2 & 0.114 & - \\
\hline & & $400 \mathrm{~m}$ versus $0 \mathrm{~m}$ & -0.873 & 0.439 & 3.953 & 1 & 0.047 & 0.418 \\
\hline & & $200 \mathrm{~m}$ versus $0 \mathrm{~m}$ & -0.200 & 0.430 & 0.216 & 1 & 0.642 & 0.819 \\
\hline & SV & Continuous & -0.033 & 0.013 & 6.065 & 1 & 0.014 & 0.968 \\
\hline & & Constant & 4.682 & 1.341 & 12.197 & 1 & 0.000 & 107.99 \\
\hline \multirow{7}{*}{ The second part (VMS-II) } & Age & Continuous & -0.112 & 0.042 & 7.272 & 1 & 0.007 & 0.894 \\
\hline & Vocation & Yes versus no & 2.066 & 0.820 & 6.351 & 1 & 0.012 & 7.896 \\
\hline & Format & - & - & - & 4.132 & 2 & 0.127 & - \\
\hline & & $\begin{array}{l}\text { Text-only versus Text } \\
\text { and graphic }\end{array}$ & -0.885 & 0.442 & 3.998 & 1 & 0.046 & 0.413 \\
\hline & & $\begin{array}{l}\text { Graphic versus Text } \\
\text { and graphic }\end{array}$ & -0.279 & 0.425 & 0.431 & 1 & 0.511 & 0.756 \\
\hline & SV & Continuous & -0.057 & 0.016 & 12.147 & 1 & 0.000 & 0.944 \\
\hline & & Constant & 6.597 & 1.775 & 13.816 & 1 & 0.000 & 733.140 \\
\hline
\end{tabular}

TABLE 4: Descriptive statistical results for LCT, LCP, LCL, LCS, and LCD.

\begin{tabular}{|c|c|c|c|c|c|c|c|c|c|c|}
\hline \multirow{2}{*}{ Variable } & \multicolumn{2}{|c|}{ LCT } & \multicolumn{2}{|c|}{ LCP } & \multicolumn{2}{|c|}{ LCL } & \multicolumn{2}{|c|}{ LCS } & \multicolumn{2}{|c|}{ LCD } \\
\hline & Mean & S.D. & Mean & S.D. & Mean & S.D. & Mean & S.D. & Mean & S.D. \\
\hline \multicolumn{11}{|l|}{ Location } \\
\hline $400 \mathrm{~m}$ & 12.3 & 4.0 & 246.9 & 187.8 & 151.5 & 94.5 & 12.1 & 6.9 & 0.5 & 0.4 \\
\hline $200 \mathrm{~m}$ & 14.1 & 6.5 & 244.5 & 155.6 & 160.2 & 101.5 & 11.5 & 5.2 & 0.5 & 0.4 \\
\hline $0 \mathrm{~m}$ & 13.2 & 5.7 & 179.0 & 65.8 & 145.2 & 65.9 & 11.2 & 3.6 & 1.1 & 0.7 \\
\hline \multicolumn{11}{|l|}{ Format } \\
\hline Text & 10.3 & 4.2 & 68.7 & 50.6 & 62.5 & 44.9 & 6.0 & 2.8 & 0.9 & 0.6 \\
\hline Graphics & 14.3 & 5.4 & 158.5 & 99.1 & 129.7 & 78.5 & 9.6 & 5.5 & 0.7 & 0.3 \\
\hline Text and graphics & 11.7 & 5.1 & 179.2 & 99.4 & 136.2 & 67.0 & 12.0 & 4.8 & 0.9 & 0.7 \\
\hline
\end{tabular}


TABLE 5: MANOVA variance analysis of lane changing behavior.

\begin{tabular}{|c|c|c|c|c|c|c|}
\hline Dependent variable & Independent variable & Type III SS & $\mathrm{DF}$ & Mean square & $F$ & Sig. \\
\hline \multirow{5}{*}{ The first part: VMS location (VMS-I) } & LCT & 38.32 & 2 & 19.16 & 0.625 & 0.539 \\
\hline & LCP & 50245 & 2 & 25212 & 1.085 & 0.345 \\
\hline & LCL & 2264.30 & 2 & 1132.15 & 0.134 & 0.875 \\
\hline & LCS & 7.92 & 2 & 3.96 & 0.131 & 0.878 \\
\hline & LCD & 3.74 & 2 & 1.87 & 8.249 & 0.001 \\
\hline \multirow{5}{*}{ The second part: VMS information formats (VMS-II) } & LCT & 142.03 & 2 & 71.01 & 2.890 & 0.065 \\
\hline & LCP & 119829 & 2 & 59915 & 7.733 & 0.001 \\
\hline & LCL & 57245.30 & 2 & 28622.69 & 6.622 & 0.003 \\
\hline & LCS & 322.44 & 2 & 161.22 & 7.762 & 0.001 \\
\hline & LCD & 0.38 & 2 & 0.19 & 0.602 & 0.551 \\
\hline
\end{tabular}

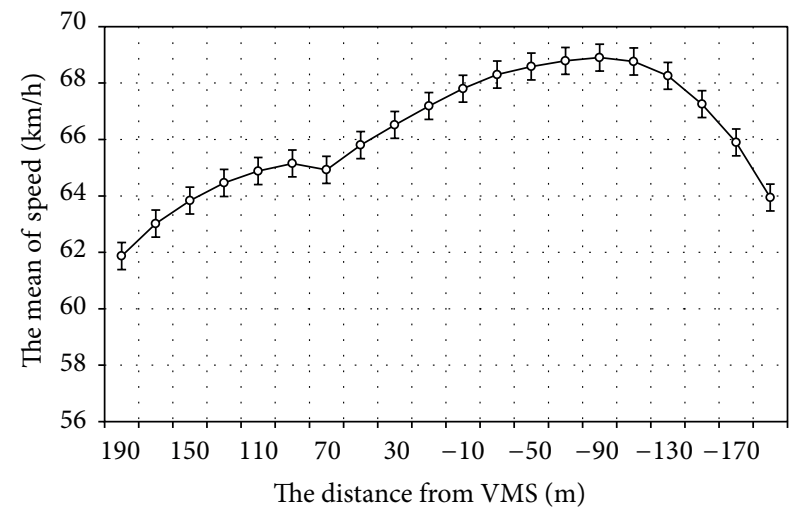

FIgURE 5: The trend of average velocities before and after VMS-I.

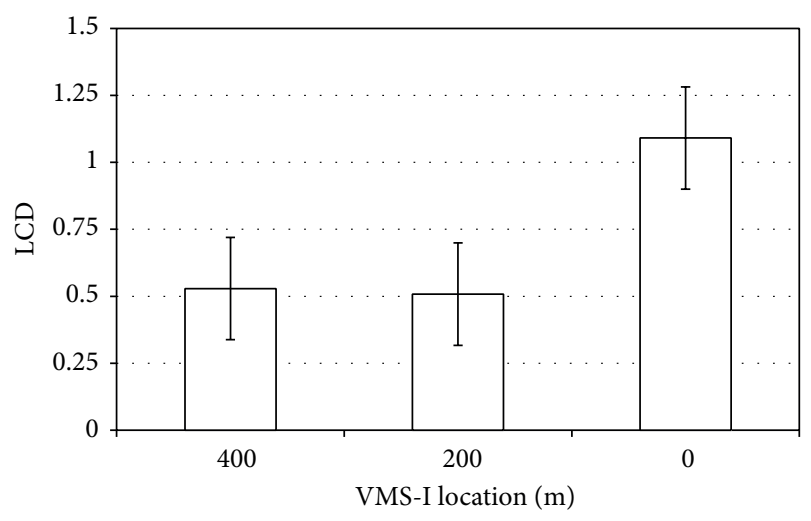

FIGURE 6: The influence of the VMS location on LCD.

LCD. The influences of VMS information format on LCT, LCP, LCL, and LCS are shown in Figure 7. It illustrates that LCT for in graphic-only format is longer than those VMS with text messages. The presumable reason is that drivers need less time to make turn decisions after perceiving the graphic information and correspondingly they can spend long time in changing lanes (see Figure 7(a)). Figures 7(b) and 7(c) show that LCP and LCL for the graphics-only and graphics-text combination formats are obviously higher than those for the text-only format, while there are no significant differences in LCP and LCL between graphics-only and graphics-text combination formats. This finding indicates that compared to VMSs with graphic information, driver need longer reaction time and decision time to make turn decisions in the text-only VMS environment so that they change lanes closer to the intersection. Figure 7 (d) shows that LCS for the text-only format is the lowest while LCS for the graphics-text combination format is the highest among the three scenarios. This finding is consistent with the trend of LCP in Figure 7(b): the farther the drivers change lane from the intersection, the higher the lane changing speed is.

\section{Conclusion and Discussion}

The main purpose of this study is to investigate how VMS position and information format affect route choice, speed control, and lane changing behaviors in the road network using a high fidelity driving simulator. Three levels of distances ranging from 0 to $400 \mathrm{~m}$ between VMS location and route-diverging intersection were designed and three kinds of information formats including text-only, graphicsonly, and combination of text and graphics were tested in the simulation experiment. The experimental results showed that both VMS location and information format profoundly influence driving behaviors.

In the past two decades, various experiments applied driving simulators to study the impact of VMS on the route choice behavior. Based on the experimental data, some route choice models were developed to evaluate the drivers' route choices under VMS and enhance network performance [29, 30]. Nevertheless, the previous studies mainly emphasized the effect of VMS on traffic operation but ignored the traffic safety. This study tried to explore the impacts of VMS on both traffic efficiency and safety. It was found if VMS is set too far away from route-diverging point, drivers are less likely to follow the VMS information to change driving routes. However, within the $200 \mathrm{~m}$ distance from route-diverging point, the effect of VMS location will be insignificant for route choice. On the other hand, if the VMS location is too close to route-diverging point, drivers would make changing route decision too late and have no sufficient deceleration distance to the diverging point. Therefore, it is suggested to position the VMS between $150 \mathrm{~m}$ and $200 \mathrm{~m}$ upstream of the 


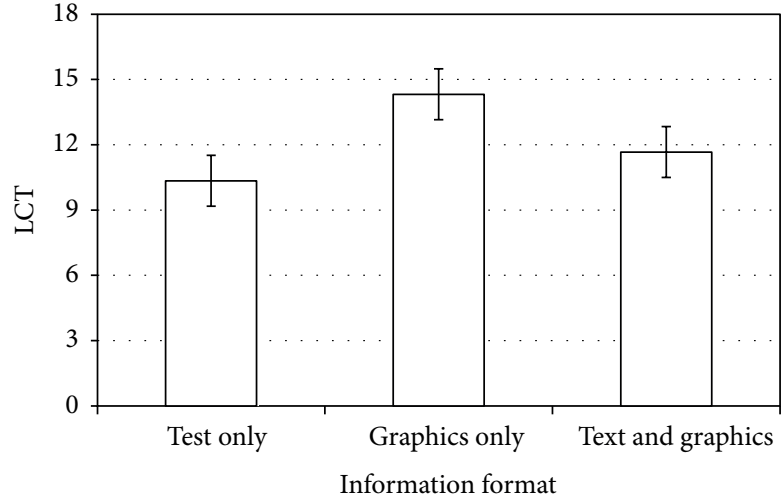

(a) LCT (lane changing time)

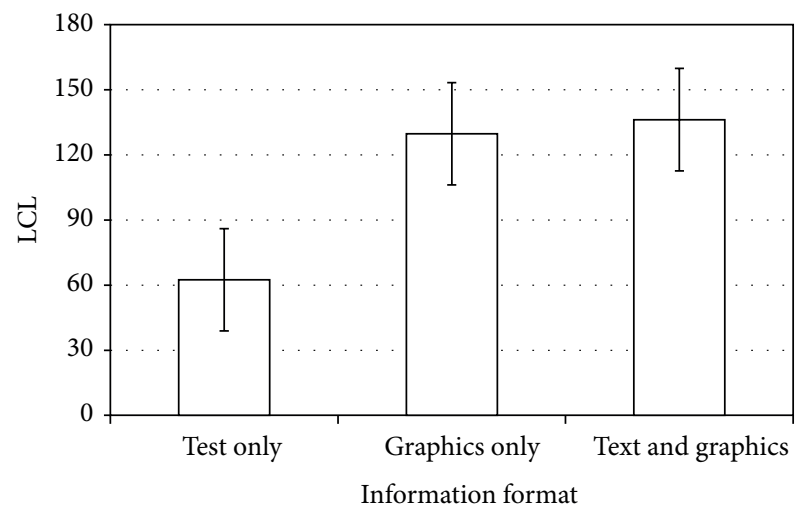

(c) LCL (lane changing length)

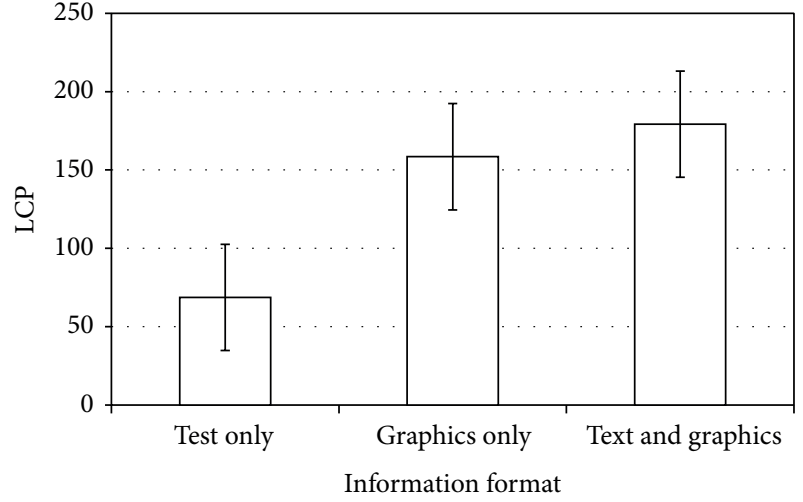

(b) LCP (lane changing position)

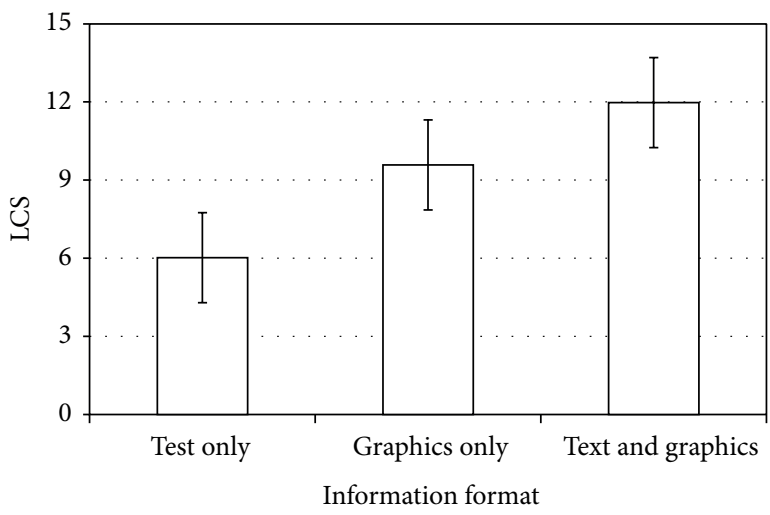

(d) LCS (lane changing speed)

FIGURE 7: The influence of the VMS information formats on LCT, LCP, LCS, and LCA.

diverging point to balance the traffic safety and operation. Furthermore, the analysis of average speed change showed that when approaching to VMS, drivers perceive the VMS information and make their route choice decisions at a $70 \mathrm{~m}$ distance upstream of VMS location.

A prior study focused on how the content of VMS affected the driving behavior, which indicated that the VMS information content, including the level of detail of relevant information, socioeconomic characteristics, network spatial knowledge, and confidence in the displayed information, significantly affected drivers' willingness to divert [31]. However, all of the terms were associated with only information content, but not the information display format. An interesting finding in this paper is that drivers are more willing to changing routes with the VMS guidance information delivered by graphics than the text-only format. Also, the text-only VMS caused drivers to change lanes later and have more abrupt deceleration behaviors during the lane changing process, compared to the VMSs with graphics information. Thus, it is better to adopt the VMS design with graphics guidance information rather than the text messages only.

Additionally, the result analyses indicated that the driver characteristics of age, gender, and vocation also have significant effects on route choice behavior in the VMS environments. It was found that the older drivers are less willing to change driving route under the VMS guidance; compared to female, the male drivers are more likely to be influenced by VMS; and the professional drivers are more likely to accept the information released by VMS.

In summary, this paper explored the relationship between driving behaviors and VMS's position and information format based on the driving simulator experiment. The findings of this study would be helpful for traffic engineers to select VMS installation locations and design VMS information delivery formats in order to optimize traffic safety and efficiency in urban road networks.

\section{Conflict of Interests}

The authors declare that there is no conflict of interests regarding the publication of this paper.

\section{Acknowledgment}

This work is financially supported by " 863 " Research Project (2011AA110303).

\section{References}

[1] G. He, ITS System Engineering Introduction, Chinese Railway Press, Beijing, China, 2004. 
[2] H. Huang, "Dynamic modeling of urban transportation networks and analysis of its travel behaviors," Chinese Journal of Management, vol. 2, pp. 18-22, 2005.

[3] R. H. M. Emmerink, P. Nijkamp, P. Rietveld, and J. N. Van Ommeren, "Variable message signs and radio traffic information: an integrated empirical analysis of drivers' route choice behaviour," Transportation Research A: Policy and Practice, vol. 30, no. 2, pp. 135-153, 1996.

[4] H. Shang, H. Huang, and Z. Gao, "Design real-time traffic information by cell transmission model," Journal of Beijing University of Aeronautics and Astronautics, vol. 34, no. 2, pp. 234-238, 2008.

[5] J. Jiang and L. Dong, "Characteristics and optimization of traffic flow in a two-off-ramp system," Acta Physics Sinica, vol. 61, no. 21, Article ID 214503, 2012.

[6] S. Zhong, H. Ma, L. Zhou, X. Wang, S. Ma, and N. Jia, "Effects of different factors on drivers' guidance compliance behaviors under road condition information shown on VMS," Transportation Research A: Policy and Practice, vol. 46, no. 9, pp. 1490-1505, 2012.

[7] P. W. Bonsall and M. Joint, "Driver compliance with route guidance advice. The evidence and its implications," in Proceedings of the Vehicle Navigation \& Information Systems Conference, vol. 2, pp. 47-59, October 1991.

[8] Z. Yuanfeng and W. Jianping, "The research on drivers' route choice behavior in the presence of dynamic traffic information," in Proceedings of the IEEE Intelligent Transportation Systems Conference (ITSC '06), pp. 1304-1309, September 2006.

[9] J. L. Adler, "Investigating the learning effects of route guidance and traffic advisories on route choice behavior," Transportation Research C: Emerging Technologies, vol. 9, no. 1, pp. 1-14, 2000.

[10] C. Yin and X. Song, "The influence of road users' personal attributes on the cognition of VMS," in Proceedings of the 1st International Conference on Transportation Information and Safety: Multimodal Approach to Sustained Transportation System Development-Information, Technology, Implementation (ICTIS '11), pp. 262-267, July 2011.

[11] J. Chen, P. Liu, and W. Wang, "Methods for en route parking guidance and information system survey in Nanjing," Urban Transport of China, vol. 4, pp. 79-83, 2006.

[12] Y. Mo and K. Yan, "Analysis of the performance of the PGIS in metropolitan area," Road Traffic and Safety, vol. 5, pp. 33-36, 2007.

[13] A. Richards and M. McDonald, "Questionnaire surveys to evaluate user response to variable message signs in an urban network," IET Intelligent Transport Systems, vol. 1, no. 3, pp. 177$185,2007$.

[14] W. Chen and P. J. Paul, "Analysis of a driver en-route guidance compliance and driver learning with ATIS using a travel simulation experiment," Research Report UCD-ITS-RR-97-12, Institute of Transportation Studies, University of California, Davis, Calif, USA, 1997.

[15] B. K. Lai and W. Wong, "SP approach toward driver comprehension of message formats on VMS," Journal of Transportation Engineering, vol. 126, no. 3, pp. 221-227, 2000.

[16] R. W. Allen, A. C. Stein, T. J. Rosenthal, D. Ziedman, J. F. Torres, and A. Halati, "Human factors simulation investigation of driver route diversion and alternate route selection using in-vehicle navigation systems," in Proceedings of the Vehicle Navigation \& Information Systems Conference, vol. 2, pp. 9-26, October 1991.
[17] R. Srinivasan and P. P. Jovanis, "Evaluation of the attentional demand of selected visual route guidance systems," in Proceedings of the 6th 1995 Vehicle Navigation and Information Systems Conference, pp. 140-146, August 1995.

[18] J. Creaser, M. Rakauskas, N. Ward, and J. Laberge, "A simulatorbased evaluation of smart infrastructure concepts of Intersection Decision Support (IDS) for rural thru-STOP scenarios," Project Number MN/RC-2007-31, Minnesota Department of Transportation, Duluth, Minn, USA, 2007.

[19] V. G. B. Kolisetty, T. Iryo, Y. Asakura, and K. Kuroda, "Effect of variable message signs on driver speed behavior on a section of expressway under adverse fog conditions-a driving simulator approach," Journal of Advanced Transportation, vol. 40, no. 1, pp. 47-74, 2006.

[20] S. L. Jamson, F. N. Tate, and A. H. Jamson, "Evaluating the effects of bilingual traffic signs on driver performance and safety," Ergonomics, vol. 48, no. 15, pp. 1734-1748, 2005.

[21] C. Lee and M. Abdel-Aty, “Testing effects of warning messages and variable speed limits on driver behavior using driving simulator," Transportation Research Record, no. 2069, pp. 55-64, 2008.

[22] A. Erke, F. Sagberg, and R. Hagman, "Effects of route guidance variable message signs (VMS) on driver behaviour," Transportation Research F: Traffic Psychology and Behaviour, vol. 10, no. 6, pp. 447-457, 2007.

[23] C. Arien, E. M. M. Jongen, K. Brijs, T. Brijs, S. Daniels, and G. Wets, "A simulator study on the impact of traffic calming measures in urban areas on driving behavior and workload," Accident Analysis and Prevention, vol. 61, pp. 43-53, 2013.

[24] L.-S. Tey, G. Wallis, S. Cloete, L. Ferreira, and Sicong, "Evaluating driver behavior toward innovative warning devices at railway level crossings using a driving simulator," Journal of Transportation Safety and Security, vol. 5, pp. 118-130, 2013.

[25] Y. Ş. Murat and N. Uludağ, "Modeling route choice behaviour in transportation networks by using fuzzy logic and logistic regression techniques," Technical Journal of Turkish Chamber of Civil Engineers, vol. 19, no. 2, pp. 4363-4379, 2008.

[26] K. Chatterjii, N. B. Hounsell, P. E. Firmin, and P. W. Bonsall, "Driver response to variable message sign information in London," Transportation Research C: Emerging Technologies, vol. 10, no. 2, pp. 149-169, 2002.

[27] C. Lee, B. Ran, F. Yang, and W. Loh, "A hybrid tree approach to modeling alternate route choice behavior with online information," Journal of Intelligent Transportation Systems: Technology, Planning, and Operations, vol. 14, no. 4, pp. 209-219, 2010.

[28] M. Yun and S. Tang, "Route diversion probability model based on guidance utility and its application," in Proceedings of the 7th International Conference of Chinese Transportation Professionals Congress 2007: Plan, Build, and Manage Transportation Infrastructures in China, pp. 627-636, May 2007.

[29] H. Dia, "An agent-based approach to modelling driver route choice behaviour under the influence of real-time information," Transportation Research C: Emerging Technologies, vol. 10, no. 56, pp. 331-349, 2002.

[30] K. V. Katsikopoulos, Y. Duse-Anthony, D. L. Fisher, and S. A. Duffy, "The framing of drivers' route choices when travel time information is provided under varying degrees of cognitive load," Human Factors, vol. 42, no. 3, pp. 470-481, 2000.

[31] S. Peeta, J. L. Ramos, and R. Pasupathy, "Content of variable message signs and on-line driver behavior," Transportation Research Record, no. 1725, pp. 102-108, 2000. 


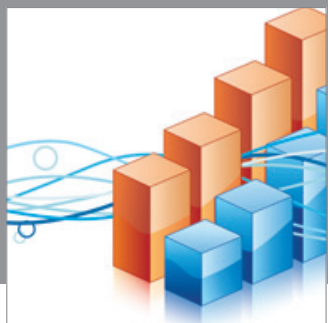

Advances in

Operations Research

mansans

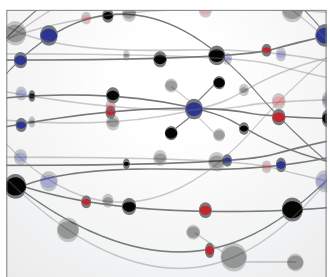

The Scientific World Journal
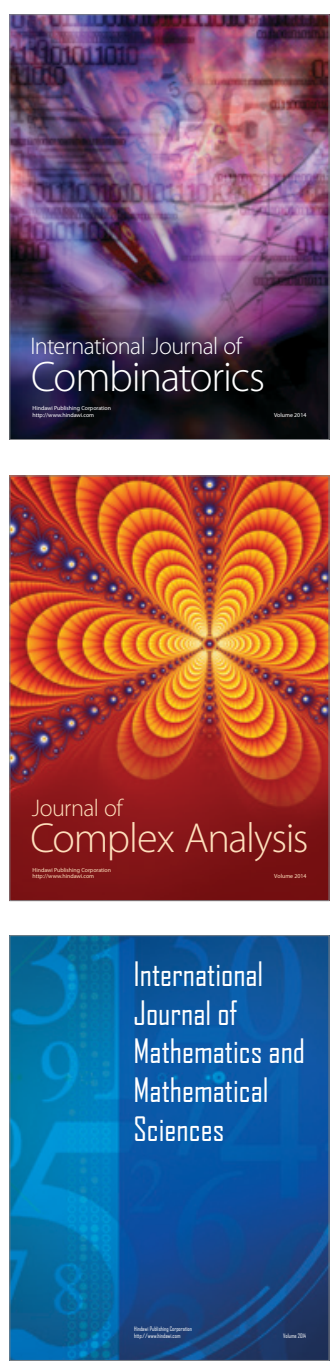
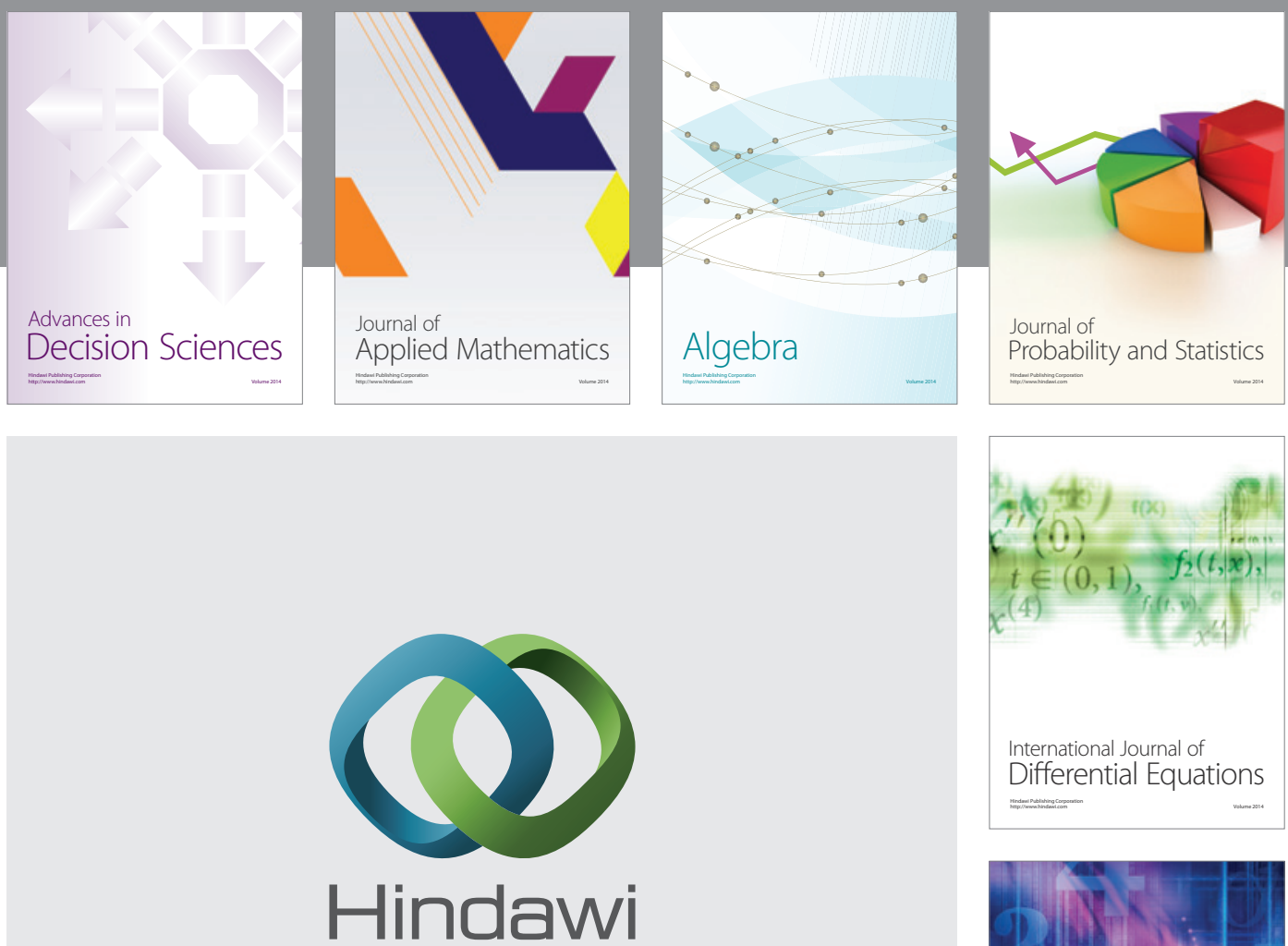

Submit your manuscripts at http://www.hindawi.com
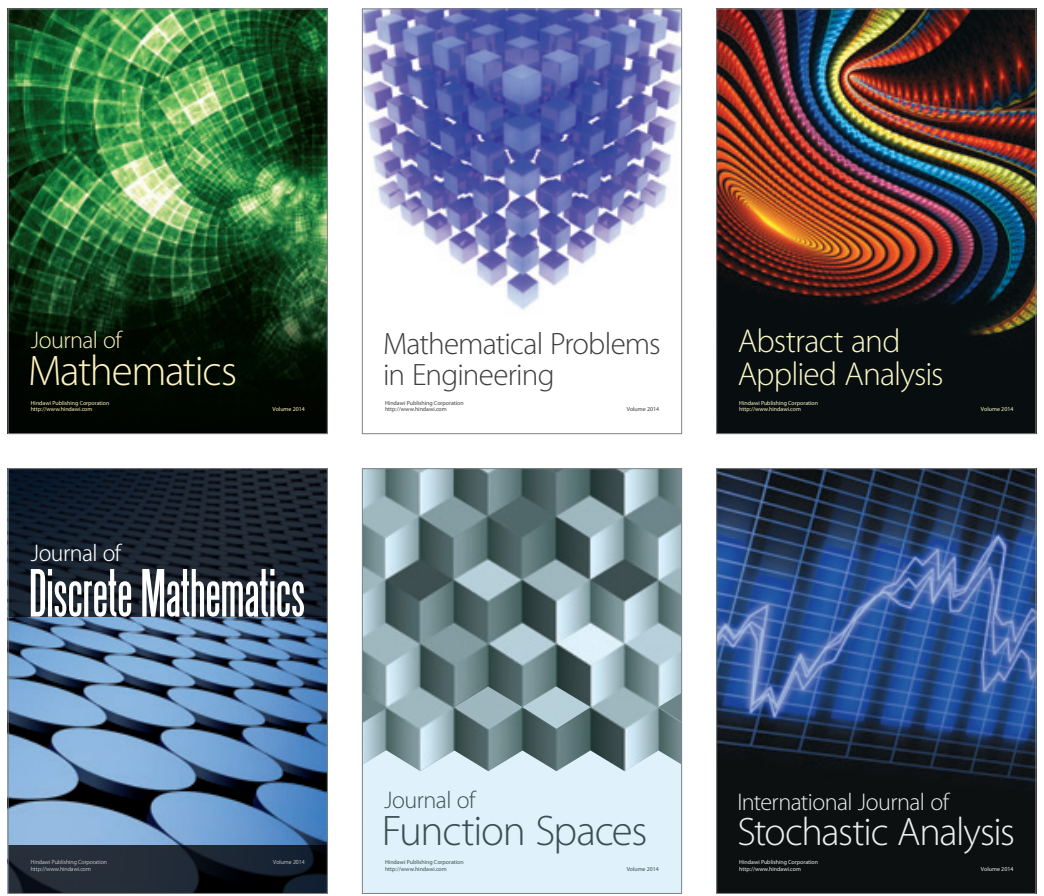

Journal of

Function Spaces

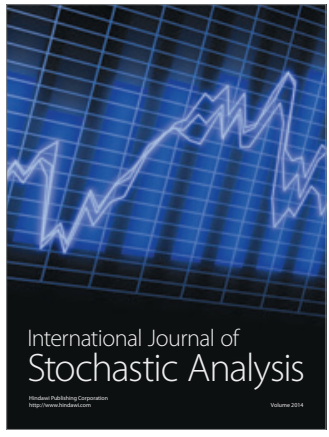

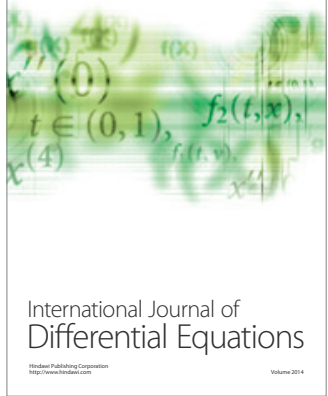
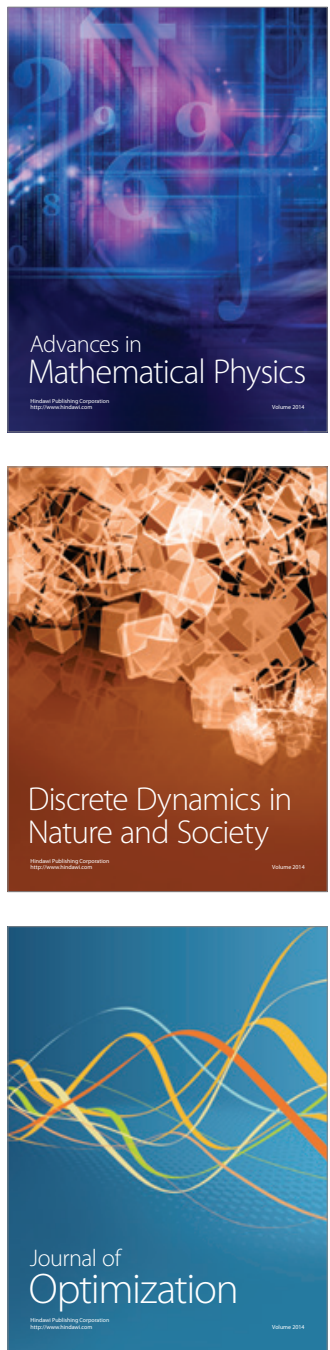